\title{
Materializing activism
}

\author{
Karin Hansson ${ }^{1}$, Teresa Cerratto Pargman ${ }^{2} \&$ Shaowen Bardzell ${ }^{3}$ \\ *11 Södertörn University, Huddinge, Sweden (E-mail: karin.hansson@sh.se); ${ }^{2}$ Stockholm University, \\ Stockholm, Sweden (E-mail: tessy@dsv.su.se); ${ }^{3}$ Penn State University, State College, University Park, \\ PA, USA (E-mail: sbardzell@psu.edu)
}

\begin{abstract}
Online activism showcases how available digital tools allow social movements to emerge, scale up, and extend globally by fundamentally enabling new forms of power. This special issue brings together eight research articles that engage with the collaborative efforts embedded in various types of activism by studying features such as the socio-technical systems involved; how the activism is organized; relations between traditional and social media; and the complex network of systems, information, people, values, theories, histories, ideologies, and aesthetics that constitutes such activisms. The articles show the spaces in which this activism materializes, and particularly their situation in several intersecting dimensions including motivation, culture, language, and infrastructure. Together, these articles reflect the methodological breadth required to materialize online activism and the need to develop a more nuanced conceptualization of the media ecologies involved. By mapping out how activism is enabled and constrained by human-computer interfaces, this special issue contributes to open up the black box of online activism.
\end{abstract}

Key Words:: Materializing activism, Net activism, Research methodology, Media ecologies

\section{Background}

Social activism consists of efforts to promote or intervene in order to bring about social change. Networked online environments can effectively support the infrastructuring of social movements and have the potential to enable more inclusive and decentralized power structures. In this regard, the popular appeal of social media has made such online environments central for social activists' communicative strategies (Askanius et al., 2011; Neumayer et al. 2016). The environmental movement has, in the past, made use of social media to engage a broad public around substantive issues ( $\mathrm{Ng}$ et al., 2020; DeLuca et al., 2016; Goodwin and Jasper 2014; Pang and Law 2017). Other examples of activism where social media has played a central role include the Arab Spring (AlSayyad and Guvenc 2015; Smidi and Shahin 2017), the Occupy Movement (Kavada 2015), and the \#MeToo movement (Askanius and Hartley 2019; Eilermann 2018; Hansson et al. 2019). More locally-situated examples are movements such as the protests for legalizing same-sex marriage in Taiwan (Bardzell et al., 2020), the Gezi protests in Turkey (Haciyakupoglu and Zhang 2015), Ukraine's Euromaidan Uprising (Bohdanova 2014), the Indignados movement in Spain (Anduiza et al. 2014), the 
Umbrella Movement in Hong Kong (Chan 2014; Lee et al. 2015; Tsui 2015), and the Save KPK movement in Indonesia (Suwana 2019).

Media and communication scholar Paolo Gerbaudo (2013) suggests that these movements are characterized by a "liquid" organization, where membership is performative and informal, and leadership is value-based rather than based on democratic structures. Like in a mob, there is no formal membership application process, clear leadership, or decision-making rules. A salient aspect of such social movements lies in the technologies and cultural practices involved; the infrastructural arrangements supporting these movements serve to circumvent formal organizational practices while also lowering the cost of political participation (Dahlberg-Grundberg 2016; Earl and Kimport 2011). Rather than being part of a political organization, political participation can here be seen as a way to work autonomously but in parallel towards goals and issues articulated by a scattered public and communicated broadly through public manifestos (Milan 2017). Another feature ascribed to these movements is the way transnational activism intersects with the national configuration of political work, such as, for example, the feminist movement or environmental movement, where shared goals can unite people across diverse national contexts (Sadowski 2016; Scharff et al. 2016).

While these socio-technical arrangements often use a hybrid of media and methods to organize and reach out, some elements of the technologies in use are more dominant in their action repertoires (Dahlberg-Grundberg 2016). Social media has also made the quantification of data easier by putting that data to new uses (Milan 2017; Milan and Velden 2016) or by providing activists with new forms of arguments when surveys can extend to millions of people, enabling a "rhetoric of collection" (Pickard and Yang 2017). \#MeToo demonstrated how activists can crowdsource data to have a massive impact on the public sphere. This has also been labeled as a scientization of activism (Kimura 2017) and provides an exciting link between activism and citizen science (Paulos et al. 2008).

Furthermore, campaigns such as \#MeToo show how online spaces can provide opportunities for victims of discrimination, harassment, and abuse to speak out, receive support from other victims, and participate in public debate around these issues. Simultaneously, research also points at the negative consequences of online spaces, rendering digital activism risky, exhausting, and overwhelming (Mendes et al. 2018). Yet activism has always been complex, and those who make a stand often put themselves in harm's way in one way or another. In particular, digital media may amplify this vulnerability that characterizes activism by exposing and surveilling users, constituting at times a digital panopticon or a means of spreading disinformation about activisms (Bradshaw and Howard 2017; Pickard and Yang 2017; Uldam 2018). Social media exposure makes it easier for companies and authorities to monitor activists' activities (Dencik et al., 2016; Trottier and Fuchs, 2015; Uldam, 2018). Through technological affordances, user regulations, and social norms, these platforms shape and control how we communicate (Klang and Madison 2016), for example, the censoring LGBTQ activism or breastfeeding activism on Facebook. 
Most often, social media users are aware of the limitations of the technology but less aware of the potential social implications (Klang and Madison 2016). The system of metrics that measure success by the number of friends, likes, retweets, and shares helps to effectively map out the network of supporters by creating a detailed overview of the online activism. Activism on social media thus takes new sorts of risks: the risk of relying on a technology that is also a means of surveillance; the risk of relying on a crowd of supporters you might never meet face to face; the risk of disinformation, particularly in relation to the unreliability of user-generated data. This might create a situation where activists mistrust information, such as during the Gezi protests in Turkey (Haciyakupoglu and Zhang 2015). In this particular case, the technology provided an opportunity to "aggregate trustworthiness" (Jessen and Jørgensen 2011) from a large number of sources, where social trust and technical affordances are interdependent (Haciyakupoglu and Zhang 2015).

Dahlberg-Grundberg (2016) suggests the concept of media ecology as a lens for capturing the coexistence of, and interdependence between, human actors and technologies, and highlight the dynamic and fragile interrelations between people, processes, practices, and artifacts. From a media-ecology perspective, the technology does not merely provide extensions or prostheses through which activists operate; it also embeds and defines the range of possible actions, indicating that media structure our actions, just like cultural norms and practices do.

These media ecologies are thus not primarily artifacts, but rather consist of social beings, structured by technology and cultural norms, that share a common interest bringing them together.

Against this background, the question is how we can understand and conceptualize these media ecologies while also contributing to the development of useful tools for political participation.

\section{Contributions}

In this special issue, we bring together the work of several researchers interested in media ecologies and the infrastructuring of social movements to closely examine a variety of cases from Sweden, China, Greece, Brazil, and the USA, with a focus on theory and methodology. Although certain platforms are often highlighted as instrumental to social movements, the articles in this special issue show how networkorganized grassroots movements do not depend on a single platform but use a complex infrastructure where culture, technology, and language interact. Another feature of this type of movement is the dynamic between the center and the periphery, where influence goes in both directions. Studying this dynamic involves particular methodological challenges, which are addressed in the first four articles on the Umbrella Movement in Hong Kong, the \#MeToo movement in Sweden, Justice for Antwon Rose II in the USA, and climate activists in Brazil.

What is it that leads activists to choose particular ICTs and not others in a situation that evolves at a fast pace and is sometimes improvised? In "Technology for 
activism: Toward a relational framework," Jun Liu examines Hongkongers' use and non-use of ICTs within the 2014 Umbrella Movement and the Anti-Extradition Bill movement to coordinate activism for pro-democratic reforms and greater government accountability in Hong Kong. The results show how the activists made strategic choices that transformed affordances, understood as action possibilities regarding specific ICTs, into aspects of a "repertoire of contention". Based on these findings, Liu formulates a relational framework that illustrates the specific dynamics of affordances behind the activists' use of ICTs.

Another movement that was largely improvised in a dynamic learning process was the \#MeToo movement, which sought to raise awareness of the widespread problem of sexual harassment and abuse. In "Organizing safe spaces: \#MeToo Activism in Sweden," Karin Hansson, Malin Sveningsson, and Hillevi Ganetz discuss how this global movement took on a special form in Sweden, where more than 100,000 people participated in over 77 interest-based petitions which had a significant impact in the media and certain industries. Such participation entailed considerable risks for those involved, and so an essential part of its organization was creating safe spaces for participants online, where they could share traumatic experiences without the risk of reprisals. Based on extensive interview material and survey data, this study reveals the connection between the opportunities provided by the interfaces, and the different social conditions within which activists from various industries worked. It achieves this by examining both the relational conditions in the interfaces and the feminist practices used to support the participants and create safe conditions for sharing. The results underline the importance of balancing the need for transparency and belonging with the need for anonymity and alienation in developing tools for large-scale activism.

Justice for Antwon Rose II is a local grassroots movement against police brutality and violence in response to the fatal shooting of a 17-year-oldAfrican-American boy at the hands of police in Pittsburgh, USA, in 2018. The shooting and subsequent trial spurred protests that continued for months on the streets and on social media, where the discursive framing of the protests evolved. In "Hybrid framing in the Justice for Antwon Rose II Movement", through a combination of interviews and network analysis, Judeth Oden Choi, James Herbsleb, and Jodi Forlizzi explore how the different technical platforms involved in the movement, populated by various networks of people, affected the framing of the activism. The study shows how these framing processes are hybrid, evolving through a combination of online and offline interactions and strategic and discursive processes. The study also reveals similarities between Justice for Antwon Rose II and both the Hongkong activism and the \#MeToo movement in Sweden, in that the activists made limited use of Twitter mainly due to concerns about safety and surveillance - except for broadcasting via a network of journalists.

In "Assembling Amazon fires through English hashtags" by Karin Skill, Sergio Passero, and Marie Francisco, the framing process is also in focus, but instead of focusing on the platforms, the authors looked at the role of different languages in the 
environmental movement in Brazil in connecting local conflicts to global publics. The study focused in particular on the use of the English hashtags \#PrayForAmazonas, \#ActForTheAmazon, and \#AmazonFire. The results show that tweets in English tended to produce more relationships than those in Portuguese and Spanish. Here, English works like a lingua franca to gather support outside Brazil, but simultaneously risks making other languages and cultures invisible. At the same time, the English-language hashtags are re-appropriated and adapted locally. In addition to the use of English, support from politicians and celebrities is essential for getting a hashtag to trend, as well as visual content such as animations and combinations of images and slogans.

What signifies online activism around specific issues such as the fight against sexism, racism, or climate change is that the commitment is motivated by a strong pathos for an issue, rather than affiliation with a political group. The fifth article in this special issue focuses on the different motivations of participants in online activism. It demonstrates how network-driven activism can unite in collective action individuals who are engaged for very disparate reasons. In "Make a difference differently: Twitter bot creators and Wikipedia transparency," Randall M. Livingstone interviewed the developers behind the transparency bots that monitor the online encyclopedia Wikipedia for edits made by government bodies and other primary stakeholders, in order to better understand the motivation and practices involved. The purpose of these bots, known as WikiEdits bots, is to increase information transparency on Wikipedia by clarifying by whom the information is produced. The developers of these activist bots act autonomously but take inspiration from each other, and they are motivated by both political reasons and the technical challenges of the Wikipedia project.

The sixth article takes a design perspective on the solidarity movement in Greece and examines how this movement can be understood and developed. In "Accounts from participatory action research with a solidarity clinic: Design implications for CSCW healthcare service design," Vasilis Vlachokyriakos, Clara Crivellaro, Hara Kouki, Christos Giovanopoulos, and Patrick Olivier report on their long-term collaboration with a self-organized social clinic within the solidarity movement. Solidarity clinics emerged following the 2008 financial crisis and collapse of Greek public services, and were established by volunteer doctors to provide primary health care for uninsured citizens. Following a Participatory Action Research (PAR) and infrastructuring approach, the researchers worked with members of the clinic for several years, organizing an oral history project to generate insights on the social and political innovation of the clinic, including design implications for the future.

A significant feature of movements organized on social media through hashtags is the enormous amounts of data that can be easily generated, and the ways in which this data can be captured and understood. Here, visualizations are an essential method for making sense of the data, while these visualizations are themselves a critical rhetorical feature of the movements. Questions about the role and potential of data visualizations are addressed in the seventh article of this special issue. In 
"Disclose to tell: A data design framework for alternative narratives", based on a study of 65 cases of data visualizations, María de los Ángeles Briones Rojas presents a guide for designers to aid them in questioning and making sense of data and to enable more critical readings of data visualizations. Most visualizations are far from the open-source ethics that data activism follows. If visualizations do not communicate the link between the data and its visualization, they risk remaining "black boxes" that contain biased representations rather than questioning them. The article therefore argues that visualizations ought to be open artifacts in order to promote a more critical data literacy.

The concluding article turns the perspective around so that the focus is not directly on cases of activism, but on research and development of the information surveillance systems monitoring and predicting "civil unrest". Technologies that monitor trends, people, and groups online based on public data sources and social media and are dedicated to forecasting protests across the globe have become increasingly sophisticated and widespread. In "Future protests made risky: Examining social media-based civil unrest prediction research and products", Gabriel Grill analyzes scholarly literature and other artifacts discussing or describing civil-unrest prediction applications and provides a conceptualization of civil-unrest prediction technology. The article shows how unrest is framed as a potential risk for companies, organizations, or governments, and as a problem solved or reduced by actors such as the military, law enforcement, and various industries rather than through political means. The analysis points to a need for critical reflection and research on the ethics and politics of protest research and applications.

\section{Conclusion}

As previous research has shown, networked-based technologies enable more liquid forms of social activism, where membership is performative and motivated by strong values (Gerbaudo 2013) and the cost of participation is lowered (DahlbergGrundberg 2016; Earl and Kimport 2011). Activists can participate autonomously towards shared goals, negotiated and communicated in online publics (Milan 2017) and uniting people globally (Hamm et al. 2021; Sadowski 2016; Scharff et al. 2016). Taken together, the articles in this special issue of CSCW illustrate the methodological breadth and flexibility required to materialize online activism and the need to develop a more complex understanding of all significant aspects of the media ecologies involved. The articles show the spaces in which this activism materializes, and particularly their situation in several intersecting dimensions including motivation, culture, language, and infrastructure. The study of such spaces requires mixed methods and different theoretical perspectives.

The first and perhaps most crucial dimension can be called motivation. The interviews and surveys referenced in these articles support previous research showing that motivation in these contexts is about strong personal affect for a political 
issue, but can also, as in the case of Wikipedia bots, be about curiosity and desire, i.e., that the work itself poses an interesting challenge.

A second dimension is culture, cultural norms, and power structures performed in interpersonal practices and expressions that can be captured or reinforced through communication technology. These can, for example, be materialized through discourses and ideologies such as language, images, and interaction patterns, which also frame the activism and situate it in wider narratives.

Another dimension which is important in a global perspective is languages and symbols, and which groups of people different languages include and exclude. Here, English functions as a lingua franca that can link local activism with global movements. Symbols in the form of famous people such as politicians and actors also play an important role in reaching out with an issue to a larger audience.

A fourth dimension is infrastructure, which can refer to concrete rules in institutional conditions, i.e., how organizational structures, economy, and regulations constrain or enable activism; and also to meeting structures or participatory design methods. Most importantly for online activism, infrastructure includes information technology, which sets protocols and rules for communication. This infrastructure provides the relations of production, and interacts to a great extent with other dimensions. Especially when it comes to social media, it is, just as with language, very much about which groups of people these infrastructures include and their extended networks; what motivates their actions; what cultural norms and power structures these groups perform; and what discourses, languages, and symbols are used to reach out.

Furthermore, as the concluding articles point out, the study of these movements and how we materialize the data gathered are not neutral but primarily characterized by ideologies and agendas. Therefore, it is crucial to aim for strong objectivity, considering how the researcher's positionality may affect their research (Harding 1995) and design practice (Hansson et al. 2018), and also to use methods and techniques that support more multidimensional reflection.

We hope that, by discussing the different dimensions of activism based on various global examples, this special issue of CSCW contributes with a starting kit for opening the black box of net activism.

\section{Acknowledgments}

The work on this special issue was conducted within the project \#MeToo activism in Sweden - Development, consequences, strategies at The School of Natural Sciences, Technology and Environmental Studies at Södertörn University, funded by the Swedish Research Council (No 2018-01824). Thanks to the participants in the workshop Materializing Activism at the 17th European Conference on Computer-Supported Cooperative Work ECSCW 2019 and the anonymous reviewers of the articles in this special issue. 
Open Access This article is licensed under a Creative Commons Attribution 4.0 International License, which permits use, sharing, adaptation, distribution and reproduction in any medium or format, as long as you give appropriate credit to the original author(s) and the source, provide a link to the Creative Commons licence, and indicate if changes were made. The images or other third party material in this article are included in the article's Creative Commons licence, unless indicated otherwise in a credit line to the material. If material is not included in the article's Creative Commons licence and your intended use is not permitted by statutory regulation or exceeds the permitted use, you will need to obtain permission directly from the copyright holder. To view a copy of this licence, visit http:// creativecommons.org/licenses/by/4.0/.

\section{References}

AlSayyad, Nezar; and Muna Guvenc (2015). Virtual Uprisings: On the Interaction of New Social Media, Traditional Media Coverage and Urban Space during the 'Arab Spring.' Urban Studies, vol. 52, no. 11, pp. 2018-2034.

Anduiza, Eva; Camilo Cristancho; and José M. Sabucedo (2014). Mobilization through online social networks: the political protest of the indignados in Spain. Information, Communication \& Society, vol. 17 , no. 6 , pp. $750-764$.

Askanius, Tina; Julie Uldam; Asa Briggs Hall; and Ansdell Street (2011). Online social media for radical politics: climate change activism on YouTube. International Journal of Electronic Governance, vol. 4, no. 1-2, pp. 69-84.

Askanius, Tina; and Jannie Møller Hartley. (2019). Framing Gender Justice. Nordicom Review, vol. 40, no. 2, 2019, pp. 19-36.

Bardzell, Jeffrey; Guo Freeman, Shaowen Bardzell, and Pei-ying Chen (2020). Join.Love: A sociotechnical genealogy of the legalization of same-sex marriage. In CHI '20: Proceedings of the 2020 CHI Conference on Human Factors in Computing Systems, Honolulu HI, USA, 25-30 April 2020. New York: ACM, pp. 1-16.

Bohdanova, Tetyana (2014). Unexpected Revolution: The Role of Social Media in Ukraine's Euromaidan Uprising. European View, vol. 13, no. 1, pp. 133-142.

Bradshaw, Samantha; and Philip N. Howard (2017). Troops, Trolls and Troublemakers: A Global Inventory of Organized Social Media Manipulation. Oxford, UK: Oxford Internet Institute.

Chan, Johannes (2014). Hong Kong's Umbrella Movement. The Round Table, vol. 103, no. 6, pp. $571-580$.

Dahlberg-Grundberg, Michael (2016). Technology as movement: On hybrid organizational types and the mutual constitution of movement identity and technological infrastructure in digital activism. Convergence, vol. 22, no. 5, pp. 524-542.

DeLuca, Kevin Michael; Elizabeth Brunner; and Ye Sun (2016). Constructing Public Space/Weibo, WeChat, and the Transformative Events of Environmental Activism in China. International Journal of Communication, vol. 10, no. June 2014, pp. 19.

Dencik, Lina; Arne Hintz; and Jonathan Cable. (2016). Towards data justice? The ambiguity of antisurveillance resistance in political activism. Big Data \& Society, vol. 3, no. 2, December 2016, pp. 205395171667967

Earl, Jennifer; and Katrina Kimport (2011). Digitally enabled social change : activism in the Internet age. Cambridge, Mass.: MIT Press. 
Eilermann, Wiebke (2018). Constructing \# MeToo: A Critical Discourse Analysis of the German News Media's Discursive Construction of the \#MeToo Movement. Malmö University, Sweden: School of Arts and Communications.

Gerbaudo, Paolo (2013). Tweets and the Streets: Social Media and Contemporary Activism. Ethnicity and Race in a Changing World, vol. 4, no. 1, pp. 105-106.

Goodwin, Jeff; and James M. Jasper (2014). The social movements reader: cases and concepts (3. ed.). Oxford: Wiley-Blackwell.

Haciyakupoglu, Gulizar; and Weiyu Zhang (2015). Social Media and Trust during the Gezi Protests in Turkey. Journal of Computer-Mediated Communication, vol. 20, no. 4, pp. 450-466.

Harding, Sandra. (1995). "Strong objectivity": A response to the new objectivity question. Synthese, vol. 104, 1995, pp. 331-349.

Karin Hansson; Malin Sveningsson; Maria Sandgren; and Hillevi Ganetz (2019). "We passed the trust on": Strategies for security in \#MeToo activism in Sweden. In ECSCW 2019: Proceedings of 17th European Conference on Computer-Supported Cooperative Work, Exploratory Papers, Demos and Posters, Salzburg, Austria, 8-12 June 2019. Siegen: EUSSET, pp. 1-19.

Hansson, Karin; Laura Forlano; Jaz Hee-jeong Choi; Carl Disalvo; Teresa Cerratto Pargman; Shaowen Bardzell; et al. (2018). Provocation, conflict, and appropriation: The role of the designer in making publics. Design Issues, vol. 34, no. 4, pp. 3-7.

Hamm, Andrea; Yuya Shibuya; Stefan Ullrich; and Teresa Cerratto Pargman (2021). What Makes Civic Tech Initiatives To Last Over Time? Dissecting Two Global Cases. In CHI '21: Proceedings of the 2021 CHI Conference on Human Factors in Computing Systems, Yokohama, Japan, 8-13 May 2021. New York: ACM, pp. 1-17.

Jessen, Johan; and Anker Helms Jørgensen (2011). Aggregated trustworthiness: Redefining online credibility through social validation. First Monday, vol. 17, no. 1-2, pp. 1-8.

Kavada, Anastasia (2015). Creating the collective: social media, the Occupy Movement and its constitution as a collective actor. Information Communication and Society, vol. 18, no. 8, pp. 107125.

Kimura, Aya H. (2017). Citizen Science in Post-Fukushima Japan: The Gendered Scientization of Radiation Measurement. Science as Culture, vol. 28, no. 3, pp. 327-350.

Klang, Mathias; and Nora Madison (2016). Domestication of online activism. First Monday, vol. 21, no. 6, pp. 1-15.

Lee, Paul S. N.; Clement Y. K. So, and Louis Leung (2015). Social media and Umbrella Movement: insurgent public sphere in formation. Chinese Journal of Communication, vol. 8, no. 4, pp. 356375.

Ng, Sarah; Shaowen Bardzell; and Jeffrey Bardzell (2020). The Menstruating Entrepreneur Kickstarting a New Politics of Women's Health. ACM Transactions on Computer-Human Interaction, vol. 27, no. 4, September 2020, pp. 1-25.

Mendes, Kaitlynn; Jessica Ringrose, and Jessalynn Keller (2018). \#MeToo and the promise and pitfalls of challenging rape culture through digital feminist activism. European Journal of Women's Studies, vol. 25, no. 2, pp. 236-246.

Milan, Stefania (2017). Data activism as the new frontier of media activism. In G. Yang and V. Pickard (Eds.), Media activism in the digital age. London: Routledge.

Milan, Stefania; and Lonneke van der Velden (2016). The Alternative Epistemologies of Data Activism. Digital Culture \& Society, vol. 2, no. 2, pp. 1-11.

Neumayer, Christina; Luca Rossi, and Björn Karlsson (2016). Contested hashtags: Blockupy Frankfurt in social media. International Journal of Communication, vol. 10, October, pp. 55585579.

Pang, Natalie; and Pei Wen Law (2017). Retweeting \#WorldEnvironmentDay: A study of content features and visual rhetoric in an environmental movement. Computers in Human Behavior, vol. 69, April 2017, pp. 54-61. 
Paulos, Eric; Marcus Foth; Christine Satchell, Younghui Kim, Paul Dourish, and Jaz Hee-jeong Choi (2008). Ubiquitous Sustainability: Citizen Science and Activism (Workshop). In UbiComp 2008: Tenth International Conference on Ubiquitous Computing, 21-24 September 2008, Seoul, South Korea. New York: ACM Press, pp. 1-35.

Pickard, Victor; and Guobin Yang (2017). Media activism in the digital age. (Pickard, Victor; and Guobin Yang, Eds.) Shaping inquiry in culture, communication and media studies. London: Routledge.

Sadowski, Helga (2016). From \#aufschrei to hatr.org: Digital-material entanglements in the context of German digital feminist activisms. Feminist Media Studies, vol. 16, no. 1, pp. 1-15.

Scharff, Christina; Carrie Smith-Prei, and Maria Stehle (2016). Digital feminisms: Transnational activism in German protest cultures. Feminist Media Studies, vol. 16, no. 1, pp. 1-16.

Smidi, Adam; and Saif Shahin (2017). Social Media and Social Mobilisation in the Middle East: A Survey of Research on the Arab Spring. India Quarterly: A Journal of International Affairs, vol. 73 , no. 2 , pp. $196-209$.

Suwana, Fiona (2019). What motivates digital activism? The case of the Save KPK movement in Indonesia. Information, Communication \& Society, vol. 23, no. 9 , pp. 1295-1310.

Trottier, Daniel; and Christian Fuchs (eds). (2015). Social media, politics and the state: protests, revolutions, riots, crime and policing in the age of Facebook, Twitter and YouTube. New York: Routledge

Tsui, Lokman (2015). The coming colonization of Hong Kong cyberspace: government responses to the use of new technologies by the umbrella movement. Chinese Journal of Communication, vol. 8 , no. 4, pp. 1-9.

Uldam, Julie (2018). Social media visibility: challenges to activism. Media, Culture and Society, vol. 40, no. 1 , pp. 41-58.

Publisher's Note Springer Nature remains neutral with regard to jurisdictional claims in published maps and institutional affiliations. 